\title{
Behaviour of the wind-turbines under lightning strikes including nonlinear grounding system
}

\author{
D. Romero ${ }^{1}$, J. Montanyà ${ }^{1}$ and A. Candela ${ }^{1}$ \\ ${ }^{1}$ Department of Electrical Engineering \\ , Technological University of Catalonia \\ Colom, 1, 08222 Terrassa (Spain) \\ phone:+34 937 398071, fax:+34 93798225 , e-mail: romero@ee.upc.es
}

\begin{abstract}
Windfarms are every day increasing in number. So wind turbines are an easy aim for cloud-to-ground lightning for two main reasons: high isokeraunic level over windfarm locations and the height and sharp of the wind turbine structure and blades. Then the turbine should facility current flowing through its main parts: blades, rotor brushes and tower without dangerous overvoltages.

Grounding should be design to derive current efficiently, but in many situations grounding is conditioned to particular location aspects such as: extension and soil resistivity. Both aspects are strongly related with grounding performance.

This paper presents an analysis of a wind turbine overvoltages. It is modelled as a transmission line with different grounding models: a constant resistance, a nonlinear model based on soil ionisation, and a windfarm interconnected grounding model. Besides not only first lightning return strokes current are considered if not, subsequent return stroke current is included too.
\end{abstract}

\section{Key words}

Grounding, wind turbines, lightning,and soil ionization.

\section{Introduction}

There are several facts that windfarms are especially lightning strokes sensitive:

- Wind turbine structure: tall with small curvature radius.

- Commonly placed in high and isolated areas.

Fatal damages in blades, generators and specially in control circuits are caused either by direct lightning strokes to wind turbines and transferred overvoltages from nearby fault location [1],[2].

The grounding system of wind turbines plays a critical role when a lightning strikes it. A good grounding design prevents against excessive overvoltages and potential gradients that can damage parts of the wind turbine and human hazards. First difficulty in grounding design is owing to high soil resistivity present where typically windfarms are placed. Furthermore, grounding topologies are variable due to topographical factors.
Typical groundings for wind turbines are arranged in a ring shape around its base and connected with the tower through its foundation (Fig. 1). In aim to reach the recommended values in standards [3],[4], difficulties arise, as the area which is practically available is smaller than the one required for the correct dimensioning. Usually vertical and horizontal electrodes are included to achieve the goals of low grounding resistance, low step voltages and touch voltages; designs could be difficult and expensive.

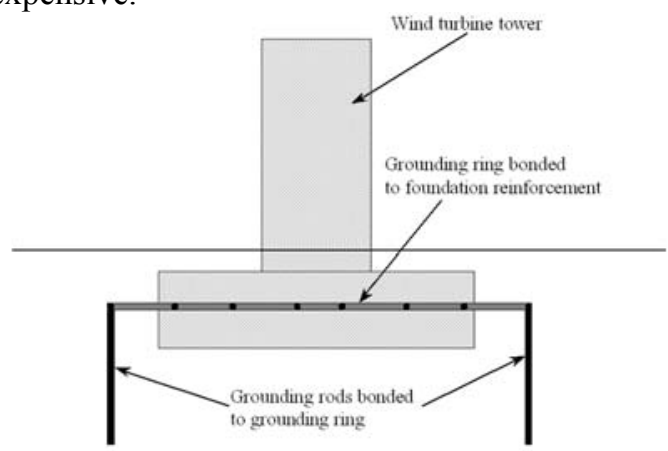

Fig. 1. Typical grounding for wind turbines

The ring electrode at the wind turbine will also act as part of the much larger grounding system. Power cables running between wind turbines will often carry an earth cable sheath. These should be used to interconnect the individual grounding system at each wind turbine. Occasionally horizontal electrodes are arranged in parallel with power cables in aim to decrease the ground resistance. All system make an extended grounding (Fig. 2 ).

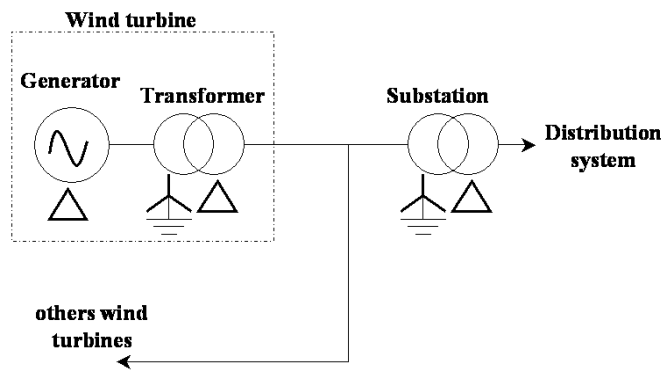

Fig. 2. Typical windfarm layout 
This paper presents a study of the possible overvoltages in a wind turbine when it is stroked by a lightning. Simple models are presented to place emphasis on transferred overvoltages. The wind turbine is modelled as a transmission line while several groundings models are included to reflect possible situations exposed above. A simplest grounding model such as pure resistive is employed to expose differences between more complex and realistic models. Other model developed includes soil ionization [5],[6] and finally and extended grounding is modelled to show the overvoltages and the inductive behaviour. Computer simulations are made with Orcad $\circledast /$ Pspice $®$ simulation package software.

\section{Models}

As described before, models presented in this paper takes into account different aspects such as the grounding path of the wind turbine, different grounding systems and the waveform of the lightning return stroke and subsequent strokes.

The lightning current travel through wind turbine from the attachment point to the earth. The current flows through the blades, sliding contacts, tower and grounding system until to come up earth.

Blades and tower are modelled as a lossless transmission line characterized by its impedance characteristic due to a particular shape. Different groundings models are employed: a constant resistance grounding, a nonlinear grounding for soil ionization and a model for extended grounding system. And finally lightning return stroke currents are adopted form [7]. Lightning current models take into account the first return stroke and one subsequent stroke with its particular wave shape characteristics. Fig. 3 shows the complete electrical wind turbine model analysed in this paper.

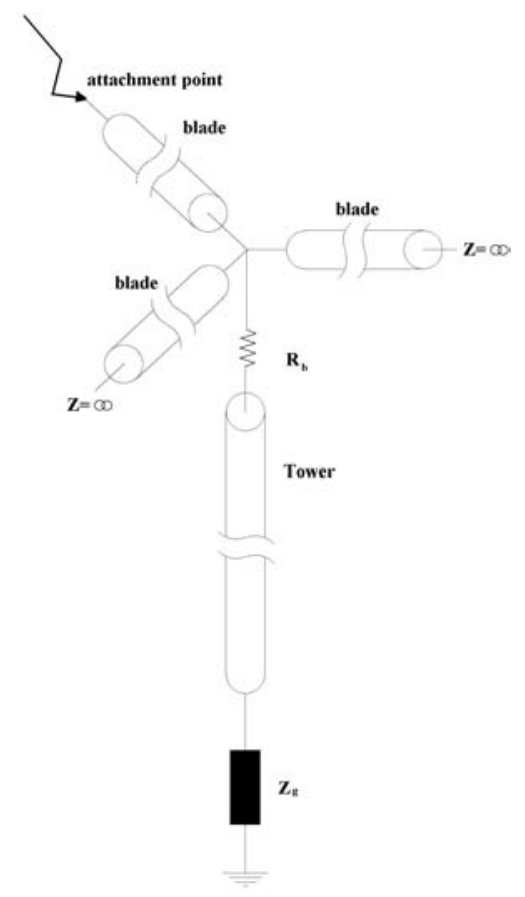

Fig. 3. Electrical wind turbine model

\section{A. Wind turbine model}

Grounding path from the attachment point to earth are considered. Blade top is normally the expected attachment point although another point could be considered. This aspect is not critical for the analysis presented. Blade and tower will be considered as a lossless transmission line. The tower is treated as a conductive cones while the blades are treated as conductive cylinder. Characteristic impedance of an electrical conductor cone and a cylinder are given by equation (1) and (2), respectively. These expressions and assumptions are adopted from [8].

$$
\mathrm{Z}_{\mathrm{B}}=60 \ln \left(\frac{H \sqrt{2}}{r_{p}}\right)
$$

where $H$ is the cone height and $r_{p}$ is the cone base radius.

The impedance of a cylinder shape.

$\mathrm{Z}_{\mathrm{T}}=60 \ln \left(\frac{2 H}{r_{c}}\right)$

where $H$ is the height of the cylinder and $r_{c}$ is its base radius.

In order to reduce the lightning current through bearings, the lightning current must be diverted via a low impedance path, and the impedance of the bearing structure must be increased by incorporating insulating materials somewhere in the current path through the bearing. Many manufacturers install alternative currents path with sliding brushes, brushes and spark gaps (Fig. 4). In this paper, blades grounding are made by a sliding contacts and brushes. Then, $R b$ represents its contact resistance, take it how constant value.

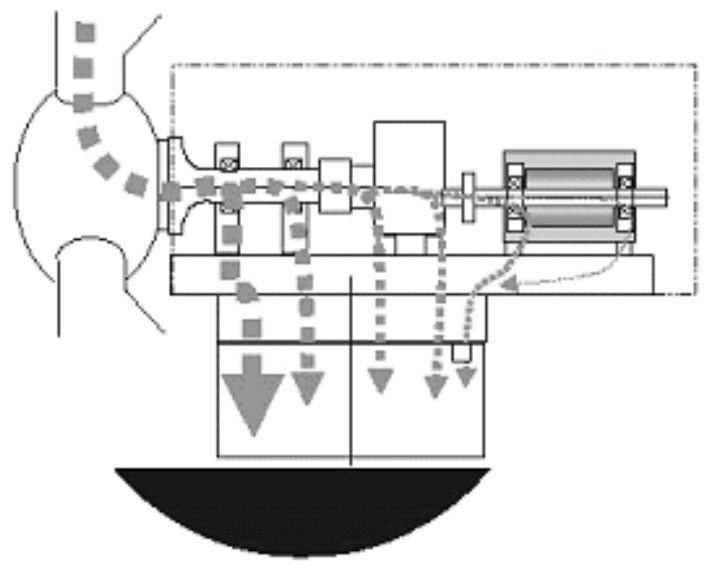

Fig. 4. Example of lightning current distribution

\section{B. Grounding model}

This work supposes a homogeneous soil medium and typical soil resistivity. Three different grounding models are considered in this work. The simplest one is based on a constant resistance, which can be used just as a first approach (Fig. 5.a). However, an accurate model has to account for a decrease of the resistance value as the 
discharge current value increases. It is well known that the resistance value is greater for small lightning currents, and its variation with respect the low current low frequency value is only significant for high soil resistivity values (Fig. 5.b).

a)

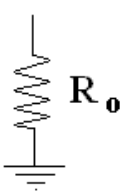

c)

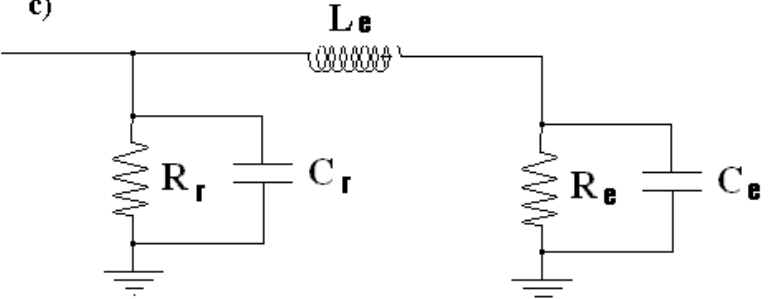

Fig.5. Grounding models: a) Pure resistance; b) Resistance with soil ionization; and c) Extended grounding system

When the soil ionisation is incorporated into the grounding model, it can be approximated by a nonlinear resistance given by [6] :

$$
\begin{cases}\mathrm{R}_{\mathrm{T}}=R_{o} & \text { for } I<I_{g} \\ \mathrm{R}_{\mathrm{T}}=\frac{R_{o}}{\sqrt{1+\frac{I}{I_{g}}}} & \text { for } I \geq I_{g}\end{cases}
$$

and critical current Ig for soil ionisation is approached by expression (4):

$$
I_{g}=\frac{E_{o} \cdot \rho}{2 \cdot \pi \cdot R_{o}^{2}}
$$

Where Eo is the ionization electric field, $\rho$ is the soil resistivity, $I$ is the current stroke through the resistance and $R o$ is the low current low frequency resistance.

When a extended grounding system is considered, the inductive behaviour cannot be neglected [9]. A highly simplified model of an extended grounding system is similar to a transmission line model. It has to account a frequency-dependent behaviour. A lumped transmission line model is proposed here ( Fig. 5.c). In this model, the effect of the length will be studied.

\section{Grounding model parameters}

Table I resumes the values adopted in this work. These values results from conclusions and assumptions in references [5],[10],[11]:
Table I. Values adopted for simulation

\begin{tabular}{|c|c|}
\hline $\boldsymbol{R o}$ & $20 \Omega$ \\
\hline $\boldsymbol{E} \boldsymbol{o}$ & $400 \mathrm{kV} / \mathrm{m}$ \\
\hline $\boldsymbol{\rho}$ & $500 \Omega \cdot \mathrm{m}$ \\
\hline $\boldsymbol{C}_{\boldsymbol{r}}$ & $11 \mathrm{nF}$ \\
\hline $\boldsymbol{L}_{\boldsymbol{e}}$ & $5 \mu \mathrm{H}$ and $20 \mu \mathrm{H}$ \\
\hline $\boldsymbol{R}_{\boldsymbol{e}}$ & $32 \Omega$ \\
\hline $\boldsymbol{C}_{\boldsymbol{e}}$ & $43 \mathrm{nF}$ \\
\hline
\end{tabular}

\section{Lightning current model}

Common lightning parameters useful to engineering applications are: return stroke peak current, number of subsequent strokes and its current peaks; wave shape and return stroke velocity; total charge and $\int i^{2} d t$. In aim to characterize overvoltages in the wind turbine, fundamental parameters in a common analysis are the peak of first return stroke current and its wave shape. As commented before, in this work subsequent return stroke current are included in the model. Data compilation from Berger et al. [7] is adopted for this study and only downward negative cloud-to-ground lightnings are considered. Table II resume the related data.

\begin{tabular}{|c|c|c|c|c|c|}
\hline \multirow[t]{2}{*}{ Parameter } & \multirow[t]{2}{*}{ Units } & \multirow{2}{*}{$\begin{array}{l}\text { Sample } \\
\text { size }\end{array}$} & \multicolumn{3}{|c|}{$\begin{array}{l}\text { Percent Exceeding } \\
\text { Tabulated Value }\end{array}$} \\
\hline & & & $95 \%$ & $50 \%$ & $5 \%$ \\
\hline $\begin{array}{l}\text { Peak current } \\
\text { (minimum } 2 \mathrm{kA} \text { ) } \\
\text { Negative first } \\
\text { strokes } \\
\text { Negative } \\
\text { subsequent } \\
\text { strokes }\end{array}$ & $\begin{array}{l}\mathrm{kA} \\
\mathrm{kA}\end{array}$ & $\begin{array}{l}101 \\
135\end{array}$ & $\begin{array}{l}14 \\
4.6\end{array}$ & $\begin{array}{l}30 \\
12\end{array}$ & $\begin{array}{l}80 \\
30\end{array}$ \\
\hline $\begin{array}{l}\text { Front duration (2 } \\
\text { kA to peak) } \\
\text { Negative first } \\
\text { strokes } \\
\text { Negative } \\
\text { subsequent } \\
\text { strokes }\end{array}$ & $\begin{array}{l}\mu \mathrm{s} \\
\mu \mathrm{s}\end{array}$ & $\begin{array}{l}89 \\
118\end{array}$ & $\begin{array}{l}1.8 \\
0.22\end{array}$ & $\begin{array}{l}5.5 \\
1.1\end{array}$ & $\begin{array}{l}18 \\
4.5\end{array}$ \\
\hline $\begin{array}{l}\text { Maximum di/dt } \\
\text { Negative first } \\
\text { strokes } \\
\text { Negative } \\
\text { subsequent } \\
\text { strokes }\end{array}$ & $\begin{array}{l}\mathrm{kA} / \mu \mathrm{s} \\
\mathrm{kA} / \mu \mathrm{s}\end{array}$ & $\begin{array}{l}92 \\
122\end{array}$ & $\begin{array}{l}5.5 \\
12\end{array}$ & $\begin{array}{l}12 \\
40\end{array}$ & $\begin{array}{l}32 \\
120\end{array}$ \\
\hline 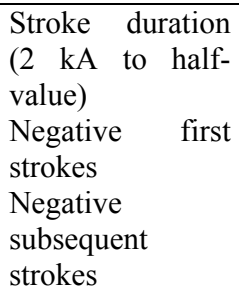 & $\begin{array}{l}\mu \mathrm{s} \\
\mu \mathrm{s}\end{array}$ & $\begin{array}{l}90 \\
115\end{array}$ & $\begin{array}{l}30 \\
6.5\end{array}$ & $\begin{array}{l}75 \\
32\end{array}$ & $\begin{array}{l}200 \\
140\end{array}$ \\
\hline $\begin{array}{l}\text { Time interval } \\
\text { Between } \\
\text { negative strokes }\end{array}$ & $\mathrm{ms}$ & 133 & 7 & 33 & 150 \\
\hline $\begin{array}{l}\text { Flash duration } \\
\text { Negative } \\
\text { (including single } \\
\text { stroke flashes) } \\
\text { Positive (only } \\
\text { single flashes) }\end{array}$ & $\begin{array}{l}\mathrm{ms} \\
\mathrm{ms}\end{array}$ & $\begin{array}{l}94 \\
39\end{array}$ & $\begin{array}{l}0.15 \\
31\end{array}$ & $\begin{array}{l}13 \\
180\end{array}$ & $\begin{array}{l}1100 \\
900\end{array}$ \\
\hline
\end{tabular}

Table II. Lightning parameters 


\section{Simulations}

Firtsly a comparison between simple constant resistance model (Fig. 6) versus nonlinear ionization model is presented (Fig. 7). Voltages due to first return stroke current in three different locations are obtained:

- At the grounding system, $V_{g}$.

- At the top of the tower, $V_{t}$.

- And the differential voltage between brushes, $V_{e}$.

The subsequent return stroke is not take account because this models (Fig. 5.a and 5.b) have not frequencydependent.

Fig. 6 shows an example of voltages in these three locations announced above for a pure resistive grounding model.

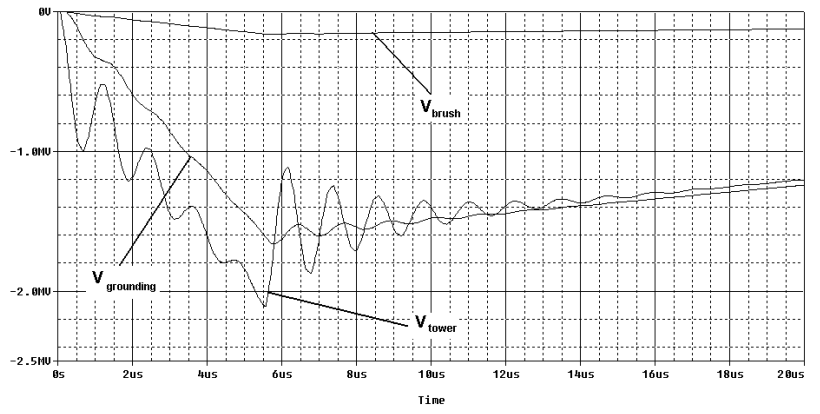

Fig. 6. Voltages for constant resistance grounding model and $I_{P}=80 \mathrm{kA}$

As a wind-turbine is a tall structure, it is modelled as a transmission line (Fig. 3), note voltage oscillations (Fig. 6) derived from current reflections.

Although a single resistance has been frequently used how first approximation, in real situations other phenomena appears, such as soil ionisation which introduces nonlinear behaviour. Fig. 7 shows another example with the effect described.

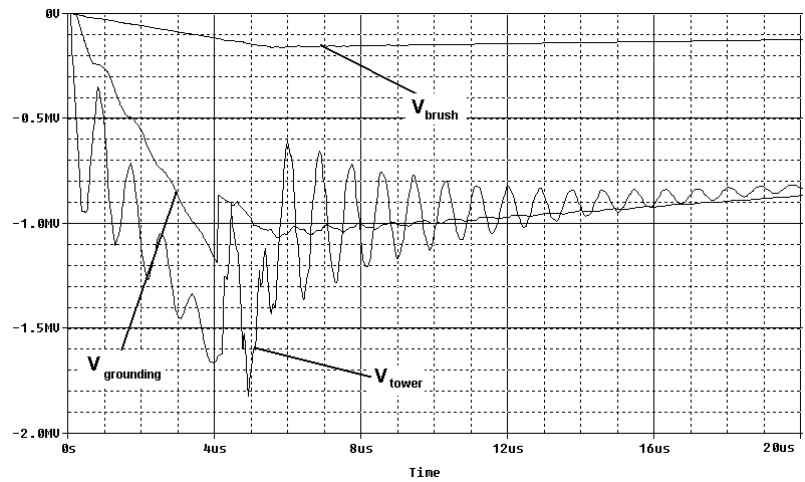

Fig. 7. Voltages for nonlinear behaviour due to soil ionisation and $I_{P}=80 \mathrm{kA}$

As described in the soil ionisation current model, when the ground current reaches the defined critical current $I_{g}$, soil breakdown appears and produces a sudden decrease of the grounding resistance. Consequently this sudden change is also present in the considered voltages (Fig. 6).

Then, as result the analysis of several peak currents and ground models a) and b); Fig. 8 presents the peak voltage evolution at three different wind-turbine locations. Graph a) $V_{g}$ represents voltages at the grounding model, b) $V_{t}$ voltages in the top of the tower and c) $V_{e}$ represents differential voltages between brushes.

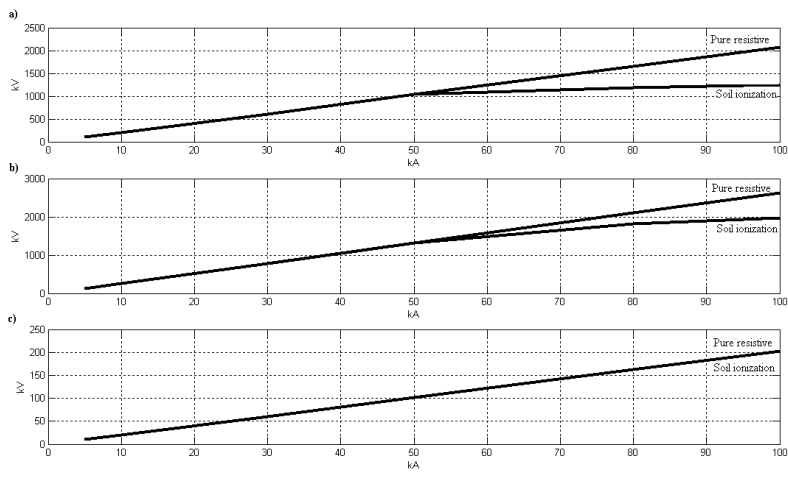

Fig. 8. Maximum voltages on grounding model, $V_{g}$; tower top, $V_{t}$; and differential voltages on brushes, $V_{e}$; for a resistive grounding model and a nonlinear model including soil ionization

It is clear to see (in Fig. 8) how since the critical current is reached voltages decrease respect a pure resistive grounding model. This effect is not present in the brushes voltage due to it is a differential voltage and possible breakdown are not considered.

In other way, considering a windfarm interconnected grounding, another interesting result appears due to the inductance of long horizontal distance grounding conductors. In this situation the lumped grounding model introduces frequency-dependent behaviour. Following results discuss about Fig. 5.c grounding model considering two $L_{e}$ inductance values: $5 \mu \mathrm{H}$ and $20 \mu \mathrm{H}$. Furthermore, first return stroke and subsequent return stroke current are distinguished. For this model, the effect of soil ionisation is not taken into account.

A double ramp has been utilized to represent the waveform described in [7] and its suitable values showed in Table II.

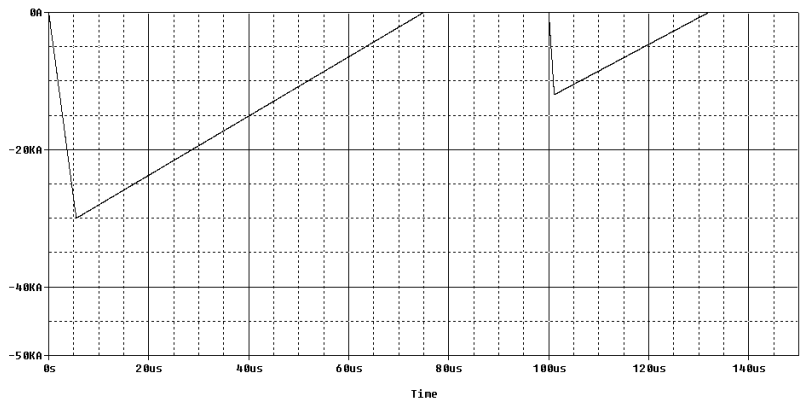

Fig. 9. Double ramp waveform. Parameters of first return stroke and subsequent return stroke 


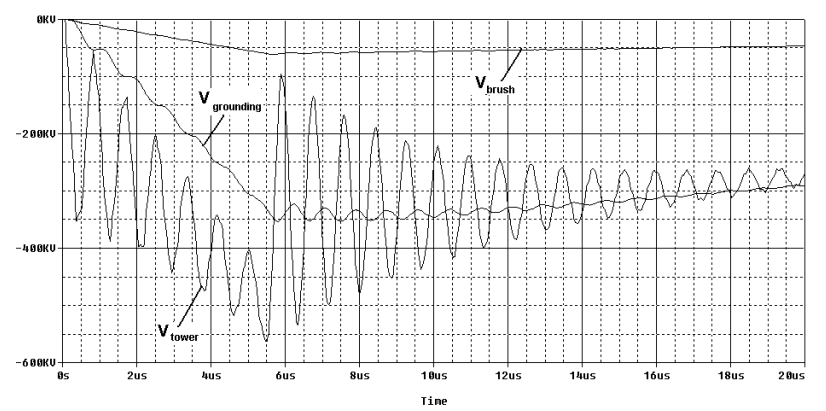

Fig. 10. First return stroke voltages evolution in different locations with $L e=5 \mu \mathrm{H}$

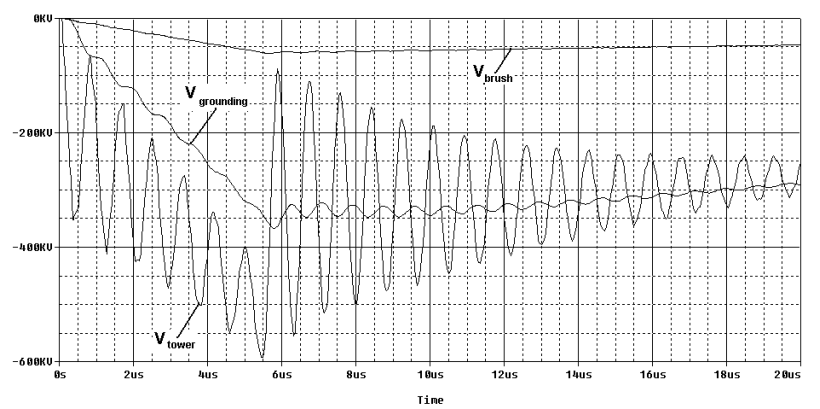

Fig. 11. First return stroke voltages evolution in different locations with $L e=20 \mu \mathrm{H}$

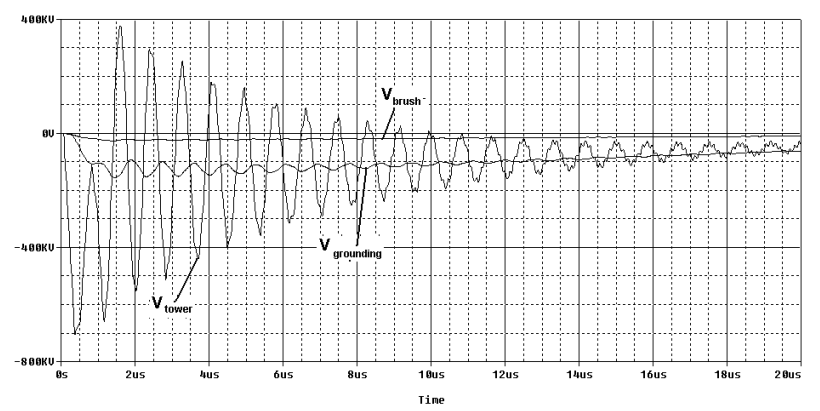

Fig. 12. Subsequent return stroke voltages evolution in different locations with $L e=5 \mu \mathrm{H}$

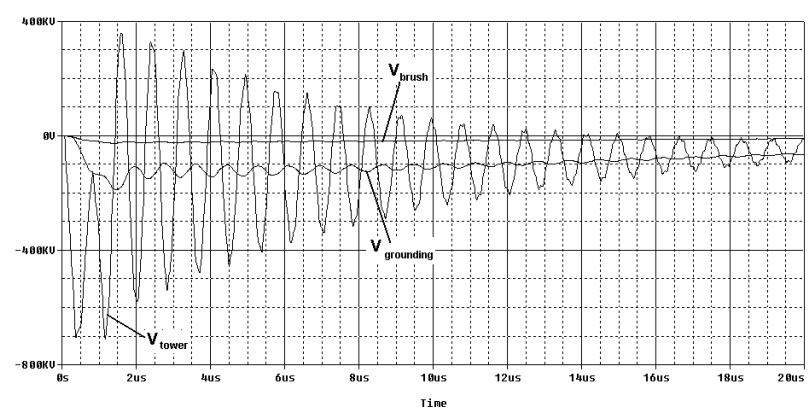

Fig. 13. Subsequent return stroke voltages evolution in different locations with $L e=20 \mu \mathrm{H}$

Figures from 14 to 16 shows maximum peak voltages for first and subsequent return stroke current of simulations in figures from 10 to 13 respectively.

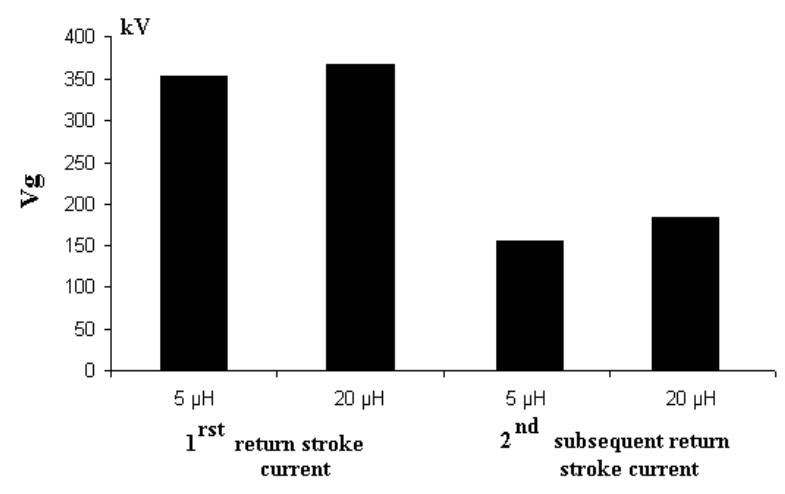

Fig. 14. Maximum grounding peak voltages

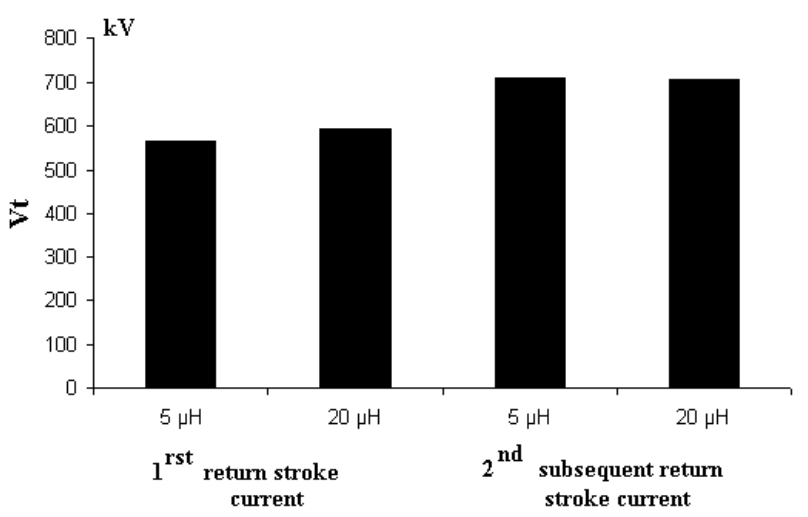

Fig. 15. Maximum tower top peak voltages

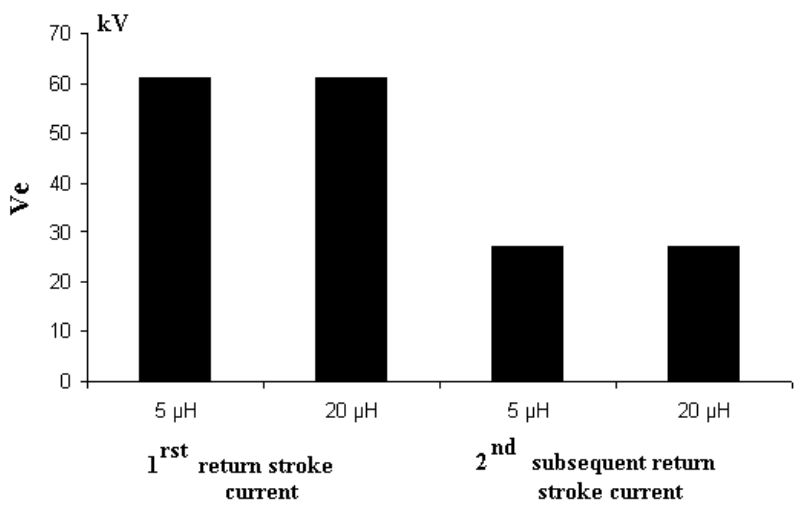

Fig. 16. Maximum brushes-rotor differential peak voltages

\section{Discussions and conclusion}

Following main conclusions are obtained from the simulations results:

- When one wind turbine grounding system is only included in the simulation, the effect of soil ionization must be used, because the influence on the overvoltages is very important.

- For a better evaluation of ionisation effect, the frequency-dependent must be included. In addition, the validation of the computer model is not an easy task. Experimental setups and field measurements can be very expensive. 
- Due to the frequency-dependent of extended grounding model and wind turbine electrical model, the front time waveform plays an important role.

- Overvoltages for subsequent return stroke are higher than the first return stroke in tower top. The inductance of the lumped model is a critical value at the performance of the grounding model. It must be accuracy measure.

- The tower is modelled as lossless transmisión line. Overvoltages have a great dependent of its characteristics values.

This paper has presented the main results of a study aimed at determining the overvoltages in characteristics locations of the wind turbines and the critical aspects for a more accurate results. Different approaches has been used for representing electrical model of the wind turbines. The main goal was to analyse the grounding behaviour and it influence in transferred overvoltages. Another characteristic has been the utilization of Orcad $\AA /$ Pspice $®$ simulation package software in order to carry out the simulation.

\section{References}

[1] I. Cotton, B. McNiff, T. Soerenson, W. Zischank, P.Christiansen, M. Hoppe-Kilpper, S. Ramakers, P. Pettersson, E. Muljadi : "Lightning protection for wind turbines", 25 ${ }^{\text {th }}$ ICLP (International Conference on Lightning Protection), Rhodes, Greece, September 2000, pp. 848-853.

[2] D. Agoris, k. Rossis, P. Vionis, N. Stavridis, E. Lignos : "Analysis of lightning incidents on wind turbines in Greece", $26^{\text {th }}$ ICLP (International Conference on Lightning Protection), Cracow, Poland, September 2002, pp. 717721.
[3] IEC 88/128 : "Wind turbine generator systems. Part 24: Lightning protection for wind turbines", 2001.

[4] IEC 61024-1-2 : "Protection of structures against lightning. Part 1-2 : General principles - Guide B - Design, installation maintenance and inspection of lightning protections systems", 1998.

[5] J.M. Prousalidis, M.P. Philippakou, N.D. Hatziargyriou, B.C. Papadias : "The effects of ionisation in wind turbine grounding modelling", $10^{\text {th }}$ MEleCon (Mediterranean Electrotechnical Conference), Vol. III, 2000, pp. 940-943.

[6] CIGRE Working Group 01 (Lightning) of Study Committee 33, "Guide to procedures for estimating the lightning performance of transmission lines", CIGRE Brochure 63, 1991.

[7] K.Berger, R.B. Anderson, H. Kroninger : "Paramèters des Coups de Foudre”, Electra, No. 41, 1975, pp. 23-37.

[8] G. Le Roy, C. Gary, B. Hutzler, J. Lalot and C. Dubanton : "Les propriétés diélectriques de l'air et les très hautes tensions", Collection de la Direction des Études et Recherches d'Électricité de France, Editions Eyrolles, 1984.

[9] I. Cotton : "Windfarm earthing", High Voltage Engineering Symposium, Conference Publication no.467, August 1999.

[10] S. Visacro and A. Soares : "Simplified models for towerfooting grounding of transmission lines for evaluation of lightning performance", $23^{\text {rd }}$ ICLP (International Conference on Lightning Protection), Firenze, Italy, September 1996.

[11] B. Hermoso, M. Aguado, X. Martinez, V. Senosiain, E. Eizaguirre and I. Eizaguirre : "Grounding of a $1500 \mathrm{~kW}$ wind turbine according with IEC standards", Int. Conf. On Grounding and Earthing, Rio de Janeiro, Brazil, November 2002, pp. 421-425. 